\title{
Identification and Detection of Methicillin Resistance in Non-Epidermidis Coagulase-Negative Staphylococci
}

\begin{abstract}
Carina Secchi ${ }^{1,2}$, Ana Lúcia Souza Antunes ${ }^{1}$, Leandro Reus Rodrigues Perez ${ }^{1}$, Vlademir Vicente Cantarelli ${ }^{2,3}$ and Pedro Alves d'Azevedo ${ }^{1}$ ${ }^{1}$ Post Graduation Program in Medical Sciences of Federal University of Health Sciences of Porto Alegre (UFCSPA); ${ }^{2}$ Weinmann Laboratory; ${ }^{3}$ Feevale Universitary Centre, NH; Porto Alegre, RS, Brazil
\end{abstract}

\begin{abstract}
The NCCLS (2004) presented a new methodology to detect, by disk-diffusion agar, oxacillin-resistance using a cefoxitin disk. We identified coagulase-negative staphylococci (SCoN) to the species level and compared the use of cefoxitin disks (30 $\mu \mathrm{g})$ with oxacillin disks $(1 \mu \mathrm{g})$, agar dilution (minimum inhibitory concentration of oxacillin) and mecA gene detection in isolates of coagulase-negative bacteria other than Staphylococcus epidermidis (SCoNne). A total of 238 SCoNne was evaluated; oxacillin-resistance (the mecA gene) was detected in $71 \%$ of the isolates. All methods gave $100 \%$ sensitivity, based on presence of the mecA gene. The specificity of the cefoxitin disk was $100 \%$, while the oxacillin disk gave a specificity of $91 \%$ and agar dilution oxacillin gave a specificity of $88 \%$. We conclude that the cefoxitin disk is an efficient test, and it is an easy method for use in clinical laboratories to detect oxacillinresistance in staphylococci.
\end{abstract}

Key-Words: Coagulase-negative Staphylococcus, cefoxitin, oxacillin, mecA gene, susceptibility diagnostic.

Coagulase-negative staphylococci (SCoN) are common pathogens of the blood stream, being frequently related to nosocomial infections, especially in neonates and immunocompromised patients; transmission usually involves medical devices, such as catheters and prostheses [1-3]. Correct identification of SCoN species has become important in clinical laboratories, since several species have been recognized as potential pathogens, especially in a nosocomial setting [4]. Although Staphylococcus epidermidis causes most SCoN infections, many other species have been identified in association with human infections, for example, Staphylococcus lugdunensis, associated with native valve endocarditis and Staphylococcus haemolyticus, which can be multiresistant, including reduced susceptibility to vancomycin [5-7].

Methicillin-resistant staphylococci are considered important agents of nosocomial infections and have frequently been isolated in hospitals throughout the world, including Brazilian hospitals [8]. Sader et al. reported that $80 \%$ of SCoN recovered from blood in Latin America were oxacillin resistant [9]. Susceptibility testing by phenotypic methods can be problematic for the detection of methicillin resistance in SCoN because of heterogeneous expression in many strains, affected by growth conditions and by the nature of the beta-lactam agents that are used [10]. For this reason, mecA gene detection by PCR is considered the gold standard for methicillin resistance detection in Staphylococcus spp. [11].

To improve accuracy in the detection of resistance, NCCLS

Received on 2 March 2008; revised 20 July 2008.

Address for correspondence: Dr. Carina Secchi. Rua Ramiro Barcelos, 910/5ºfloor. Phone: 55-051-33143846. Fax: 55-051-33117813. Porto Alegre, RS, Brazil, Zip code: 90035001.E-mail: csecchi@gmail.com. Financial support: CNPq, UFCSPA, Weinmann Laboratório. Part of this paper was presented at the $107^{\text {th }}$ General Meeting of the American Society for Microbiology (Toronto, Can, 2007).

The Brazilian Journal of Infectious Diseases 2008;12(4):316-320. (C) 2008 by The Brazilian Journal of Infectious Diseases and Contexto Publishing. All rights reserved.
2004 recommended that clinical laboratories should use cefoxitin disk ( $30 \mu \mathrm{g})$ tests for detection of oxacillin resistance in Staphylococcus spp. [12]. Several studies have been performed to compare results obtained with cefoxitin and oxacillin disks and how they correlate with the presence of the mecA gene in Staphylococcus spp. [13-15]. We identified all SCoN to the species level and compared the use of cefoxitin disks (30 $\mu \mathrm{g}$ ) with oxacillin disks $(1 \mu \mathrm{g})$, agar dilution (MIC of oxacillin), and mecA gene detection, in isolates of coagulasenegative other than Staphylococcus epidermidis (SCoNne).

\section{Material and Methods}

\section{Bacterial Isolates}

A total of 238 samples of SCoNne were analyzed, from a collection of samples of SCoN of the Gram-positive Cocci Laboratory of the UFCSPA, stored in skim milk (Difco, Detroit) at $-20^{\circ} \mathrm{C}$. The samples were obtained from blood cultures collected consecutively, between 2002 and 2004, in the Complexo Hospitalar Santa Casa, Porto Alegre, RS, Brasil.

\section{Identification of Isolates}

The isolates were cultured in Tryptic Soy agar (Oxoid, Basingstoke, UK), supplemented with $5 \%$ sheep blood, for $24 \mathrm{~h}$ at $35^{\circ} \mathrm{C}$; colony morphology, hemolytic activity and purity were evaluated. Subsequently, phenotypic tests were evaluated by the conventional method proposed by Kloss \& Bannerman 1994, and modified by Bannerman 2003, which consists of a set of biochemical tests that determine the utilization of coagulase, catalase, alkaline phospatase, ornithine decarboxylase, urease, PYR (pyrrolidinyl- $\beta$ naphthylamide hydrolysis), and acid production from carbohydrates (trehalose, mannitol, mannose, sucrose, maltose, lactose, and cellobiose) [16,17]. Anaerobic growth in thioglycolate and susceptibility to novobiocin, polymyxin $\mathrm{B}$, bacitracin, desferrioxamine and fosfomycin using disk diffusion tests were evaluated [18]. Quality control was performed with S. epidermidis ATCC 12228. The samples that gave variable results in the phenotypic test 
identifications, or to confirm less frequent species, were run through an automated method of identification (Microscan Walkway; Dade Behringer, Deerfield, IL, USA). The automated results that gave a low percentage certainty of species identification were submitted to determination of the sodA gene by PCR amplification and sequencing with specific primers: $d^{1}$ : 5'CCITAYICITAYGAYYGCIYTIGARCC3' and d' ${ }^{2}$ 5'ARRTARTAIGCRTGYTCCCAIACRTC-3' [19].

\section{Disk Diffusion Test (DD)}

The suspensions were adjusted to a 0.5 McFarland standard for each sample to perform the disk diffusion method (Kirby-Bauer) on Mueller-Hinton agar plates (Difco, Laboratories, Detroit, Mich), using cefoxitin (30 $\mu \mathrm{g})$ and oxacillin (1 $\mu \mathrm{g}$ ) disks (Oxoid, Basingstoke, UK), according to the criteria recommended by CLSI 2005 [20]. The plates were incubated at $35^{\circ} \mathrm{C}$ and screened after $24 \mathrm{~h}$.

\section{Agar Dilution Test}

Determination of the minimum inhibitory concentration (MIC) for oxacillin was performed by bacterial suspension (0.5 McFarland), diluted 1:10 in saline solution and inoculated on Mueller-Hinton agar plates supplemented with $2 \% \mathrm{NaCl}$ by using Steers replicator. Concentrations of $0.125 \mu \mathrm{g} / \mathrm{mL}-4$ $\mu \mathrm{g} / \mathrm{mL}$ of oxacillin (Sigma Chemical Co, St. Louis, USA) were used for determination of the MIC of oxacillin. The plates were incubated at $35^{\circ} \mathrm{C}$ and screened after $24 \mathrm{~h}$.

\section{Detection of mecA Gene}

Staphylococcal DNA was extracted in guanidine isothiocyanate solution (Invitrogen, Carlsbad, USA) and the mecA gene was detected by PCR with specific primers: mecA $^{1}$ : 5' TGGCTATCGTGTCACAATCG, mecA ${ }^{2}$ : 5' CTGGAACTTGTT GAGCAGAG [21]. Subsequently, $2 \mu \mathrm{L}$ of bacterial DNA was added to the PCR tube, followed by $23 \mu \mathrm{L}$ mixture containing $0.2 \mathrm{mM}$ of each of the deoxynucleoside triphosphates (dNTPs), 1 X PCR buffer [20 mM Tris-HCl, 50 $\mathrm{mM} \mathrm{KCl}(\mathrm{pH} \mathrm{8,4)],} 1.0 \mathrm{U}$ of Taq polymerase (Invitrogen, Carlsbad, USA), $1.5 \mathrm{mM} \mathrm{MgCl}_{2}$; and $0.2 \mu \mathrm{M} / \mu \mathrm{L}$ of each primer. PCR was performed under the following conditions: initial denaturation for $2 \mathrm{~min}$ at $95^{\circ} \mathrm{C}$, followed by 35 cycles of amplification: denaturation at $95^{\circ} \mathrm{C}$ for 20 s, annealing at $53^{\circ} \mathrm{C}$ for 30s, extension at $72^{\circ} \mathrm{C}$ for $40 \mathrm{~s}$ and a final extension step at $72^{\circ}$ for $10 \mathrm{~min}$, using a PTC 200 thermocycler (MJ Research, GMI, Minnesota, USA). A positive result was indicated by the presence of a 310-bp amplified DNA fragment when compared with a 100-bp DNA ladder (Invitrogen, Carlsbad, USA). The DNA fragment was revealed by electrophoresis on $1.5 \%$ agarose gel, staining with ethidium bromide, and visualization under ultraviolet light. Quality control was performed with $S$. aureus ATCC 25923 (mecA-negative) and S. aureus ATCC 33591 (mecA positive).

\section{Slide Latex Agglutination Test}

Detection of PBP2a was performed with the latex agglutination test Slidex MRSA Detection (bioMérieux, l’Etoile, France), following the manufacturer's instructions. This test was performed only for samples that showed discrepant results between cefoxitin and oxacillin in our tests.

\section{Results}

A total of 238 isolates were identified as SCoNne. The most frequent organism was S. haemolyticus (42\%-100/238), followed by S. hominis-hominis (29.4\%-70/238) and S. warneri (7.5\%-18/238). The prevalence of SCoNne species and of the mecA gene are shown in Table 1 . Various phenotypic methods were employed to identify SCoN, including morphology of the colonies, antimicrobial resistance, hemolytic activity, enzymatic activity in different substrates and acid production from carbohydrates. The tests were followed for 24,48 , and $72 \mathrm{~h}$ and 7 days at $35^{\circ} \mathrm{C}$, identifying 238 strains of SCoNne. The most prevalent species, $S$. haemolyticus, was easily identified by a simple scheme, using hemolytic activity, a PYR test and urea and mannose tests.

By conventional and commercial methods of species identification, in addition to giving low accuracy (50\%-70\%), are more troublesome and require more incubation time [19]. Among the isolates, 75\% (178/238) were identified only by phenotypic methods and 25\% (60/238) by a commercial method. Molecular methods based on the analysis of products from PCR have been developed for SCoN identification, giving improved consistency and speed $[19,22]$. Species that are more difficult to identify by phenotypic or commercial methods, such as $S$. caprae and $S$. equorum, were identified by PCR and sodA gene sequencing. Although only 3\% (8/38) of isolates were identified by the sodA gene, the concordance between this method and the commercial method was $62.5 \%$ (5/8).

The mecA gene was detected in $71 \%(169 / 238)$ of the SCoNne isolates. Concordance between cefoxitin disk, oxacillin disk, agar dilution and mecA gene detection was found in $96 \%(229 / 238)$ of the strains. However, discrepancies between the phenotypic methods and mecA gene detection were observed in 4\% (9/238, Table 2). Disagreement between the oxacillin disk test and mecA gene detection was observed in $2.5 \%(6 / 238)$ of the isolates. The cefoxitin disk gave $100 \%$ sensitivity and specificity. The oxacillin disk also gave a sensitivity of $100 \%$ and a specificity of $91 \%$. The sensitivity of agar dilution was $100 \%$, with a specificity of $88 \%$. When the results obtained in the disk diffusion test and agar dilution were compared, we found that they gave the same sensitivity. However, the specificity, VPP and VPN results were better with the cefoxitin disk (Table 3).

The cefoxitin disk test was proposed in 2001 as an option for the detection of oxacillin resistance mediated by the mecA gene, considering that many laboratories do not have a latex agglutination test or a PCR technique for routine use [23]. Earlier studies indicated that the cefoxitin disk is a helpful tool for the detection of oxacillin resistance, with 99\%-100\% sensitivity and $96 \%$ specificity to predict the mecA gene in $S$. aureus and SCoN [14,24,25]. 
Table 1. Occurence of the mecA gene among 238 SCoNne isolates.

\begin{tabular}{|c|c|c|c|c|c|c|}
\hline \multirow[t]{2}{*}{ Species } & \multicolumn{2}{|c|}{ Occurrence } & \multicolumn{2}{|c|}{ mecA Pos Isisolates } & \multicolumn{2}{|c|}{ mecA Neg isolates } \\
\hline & $\mathbf{N}$ & $\%$ & $\mathbf{N}$ & $\%$ & $\mathbf{N}$ & $\%$ \\
\hline S. haemolyticus & 100 & 42.0 & 91 & 91.0 & 9 & 9.0 \\
\hline S. hominis-hominis & 70 & 29.4 & 53 & 76.0 & 17 & 24.0 \\
\hline S. warneri & 18 & 7.6 & 7 & 39.0 & 11 & 61.0 \\
\hline S. capitis-capitis & 9 & 3.7 & 1 & 11.0 & 8 & 89.0 \\
\hline S. sciuri & 9 & 3.7 & 1 & 11.0 & 8 & 89.0 \\
\hline S. saprophyticus & 6 & 2.5 & 4 & 67.0 & 2 & 33.0 \\
\hline S. hominis novobiosepticus & 6 & 2.5 & 5 & 83.0 & 1 & 17.0 \\
\hline S. capitis urealyticus & 5 & 2.1 & 2 & 40.0 & 3 & 60.0 \\
\hline S. cohnii cohnii & 4 & 1.6 & 0 & 0.0 & 4 & 100.0 \\
\hline S. xylosus & 3 & 1.3 & 3 & 100.0 & 0 & 0.0 \\
\hline S. cohnii urealyticus & 3 & 1.3 & 1 & 33.0 & 2 & 67.0 \\
\hline S. lugdunensis & 1 & 0.4 & 0 & 0.0 & 1 & 100.0 \\
\hline S. simulans & 1 & 0.4 & 1 & 100.0 & 0 & 0.0 \\
\hline S. auricularis & 1 & 0.4 & 0 & 0.0 & 1 & 100.0 \\
\hline S. caprae & 1 & 0.4 & 0 & 0.0 & 1 & 100.0 \\
\hline S. equorum & 1 & 0.4 & 0 & 0.0 & 1 & 100.0 \\
\hline Total & 238 & 100 & 169 & 71.0 & 68 & 29.0 \\
\hline
\end{tabular}

Table 2. Discrepant results for nine SCoNne isolates that are mecA and latex (PBP2a) negative, by phenotypic methods (DD and MIC).

\begin{tabular}{lcccc}
\hline Species & Isolate number & DD cefoxitin & DD oxacillin & $\begin{array}{c}\text { Agar dilution } \\
\text { (MIC } \boldsymbol{\mu g} / \mathbf{m L})\end{array}$ \\
\hline S. sciuri & 224 & $\mathrm{~S}$ & $\mathrm{R}$ & $0.5(\mathrm{R})$ \\
S. sciuri & 247 & $\mathrm{~S}$ & $\mathrm{R}$ & $0.5(\mathrm{R})$ \\
S. sciuri & 201 & $\mathrm{~S}$ & $\mathrm{R}$ & $0.5(\mathrm{R})$ \\
S. sciuri & 216 & $\mathrm{~S}$ & $\mathrm{R}$ & $0.25(\mathrm{~S})$ \\
S. saprophyticus & 327 & $\mathrm{~S}$ & $\mathrm{~S}$ & $0.5(\mathrm{R})$ \\
S. saprophyticus & 633 & $\mathrm{~S}$ & $\mathrm{~S}$ & $0.5(\mathrm{R})$ \\
S. cohnii cohnii & 226 & $\mathrm{~S}$ & $\mathrm{~S}$ & $0.5(\mathrm{R})$ \\
S. cohnii cohnii & 244 & $\mathrm{~S}$ & $\mathrm{R}$ & $0.5(\mathrm{R})$ \\
S. cohnii-cohnii & 605 & $\mathrm{~S}$ & $\mathrm{R}$ & $0.5(\mathrm{R})$ \\
\hline
\end{tabular}

$\mathrm{R}=$ resistant; $\mathrm{S}=$ susceptible.

Table 3. Sensitivity, specificity and positive and negative predictive values for phenotypic methods in comparison with the PCR results for detection of oxacillin resistance among SCoNne isolates.

\begin{tabular}{|c|c|c|c|c|c|c|}
\hline & \multicolumn{2}{|c|}{ DD cefoxitin } & \multicolumn{2}{|c|}{ DD oxacillin } & \multicolumn{2}{|c|}{ MIC oxacillin } \\
\hline & $\mathbf{N}$ & $\%$ & $\mathbf{N}$ & $\%$ & $\mathbf{N}$ & $\%$ \\
\hline Sensitivity & 169/169 & 100 & $169 / 169$ & 100 & $169 / 169$ & 100 \\
\hline Specificity & 69/69 & 100 & 63/69 & 91 & 61/69 & 88 \\
\hline VPP & $169 / 169$ & 100 & $169 / 175$ & 97 & $169 / 177$ & 95 \\
\hline VPN & 69/69 & 100 & 69/69 & 100 & 69/69 & 100 \\
\hline Accuracy & 238/238 & 100 & $232 / 238$ & 97 & $230 / 238$ & 97 \\
\hline
\end{tabular}

\section{Discussion}

We evaluated a higher number of isolates of SCoNne than other studies performed in Brazil, and we found high rates of resistance to oxacillin by PCR (71\%) in these isolates, though earlier studies also included isolates of S. epidermidis [2628]. In our study, among the SCoNne isolates, 100 were identified as $S$. haemolyticus, with $91 \%$ presenting a mecAgene-positive PCR result. Other studies have shown that $S$. haemolyticus and $S$. epidermidis are the species most frequently associated with antimicrobial agent resistance $[7,8]$. A study performed by Palazzo \& Darini in 2006 described a sensitivity of $92.5 \%$ to both cefoxitin and oxacillin disk tests, 
a specificity of $98.6 \%$ to cefoxitin disks and $96 \%$ to oxacillin disks. In this study, six isolates showed a false negative result in the cefoxitin disk test (five isolates of $S$. epidermidis and one isolate of $S$. caprae) [29]. Perazzi et al. in 2006 found a lower sensitivity for the cefoxitin disk (84\%) than that obtained with the oxacillin disk (87\%), in a study performed with isolates of SCoN other than S. saprophyticus. The specificity of the cefoxitin disk was $100 \%$ [30].

Among the species for which there were discrepancies between the tests, susceptibility to cefoxitin disk with resistance with oxacillin disk was observed in 44\% (4/9) isolates of $S$. sciuri, all of them giving negative results in a PCR of the mecA gene. Oxacillin resistance was observed in three of these isolates and oxacillin susceptibility in one of them with an agar dilution test. Resistance to oxacillin was observed in $33 \%(2 / 6)$ of $S$. saprophyticus isolates by the agar dilution test. The PCR results for the mecA gene were negative in these isolates, which showed susceptibility to cefoxitin and oxacillin by disk diffusion. Seventy-five percent (3/4) of the isolates identified as $S$. cohnii-cohnii, which gave a negative PCR for the mecA gene, had discrepancies with the oxacillin disk and/or agar dilution results. Two of these isolates were resistant to oxacillin by disk and agar dilution, and one of them was resistant only by agar dilution. All of them were susceptible when tested with the cefoxitin disk. Results obtained for the other species did not differ among the methods (Table 2). Pottumarthy et al. in 2005 found 3\% of very major errors with the cefoxitin disk test and $4 \%$ with the oxacillin disk test [31]. We only found major errors (falseresistance) with the oxacillin disk in $2.5 \%$ of the isolates, including S. sciuri, S. saprophyticus and S. cohnii-cohnii. Similar discrepancies between phenotypic and genotypic results have been described for S. saprophyticus, S. cohnii, S. warneri, S. capitis, S. lugdunensis and S. xylosus [32].

Detection of oxacillin resistance in SCoN is a challenge for clinical laboratories because many false negative results can be attributed to heterogeneous resistance to oxacillin expressed by this type of organism [26,29,33]. The cefoxitin disk test is considered a better predictor for resistance than oxacillin, especially when there is heteroresistance to oxacillin. This can be explained by the fact that cefoxitin has a strong ability to induce PBP2a and also has a high affinity for PBP4, a protein involved in resistance in Staphylococcus spp. These organisms, although less frequent in the laboratory routine, could be more affected by the lower specificity of the oxacillin disk diffusion test and/or the oxacillin agar dilution test [32,34]. According to NCCLS 2001, the disk diffusion test with oxacillin is not recommended for $S$. saprophyticus, since most isolates that are $m e c A$ gene negative can express resistance based on phenotypic methods [35]. The S. saprophyticus isolates evaluated in our study gave similar results when cefoxitin/ oxacillin disk diffusion and $m e c A$ gene detection were compared. However, agar dilution results showed poor concordance with the mecA gene test, since two isolates were resistant to oxacillin based on agar dilution (MIC of $0.5 \mu \mathrm{g} / \mathrm{mL}$ ).
Studies performed to detect resistance in Staphylococcus spp. have demonstrated discrepancies between the phenotypic methods and the gold-standard, especially in SCoN. False positive results (resistant isolates that do not harbor the mecA gene) can be associated with hyper-production of $\beta$-lactamases, resulting in hydrolysis of the beta-lactam agent and changes in PBPs other than PBP2a [33]. Total concordance between the latex agglutination test for PBP2a and mecA gene detection by PCR has been observed in isolates that showed false resistance with oxacillin disk diffusion or dilution. The PBP2a test was performed with and without induction, and identical results were observed with the different methods [32,36]. When we analyzed the false positive results obtained with agar dilution (Table 2), we found that eight isolates gave MICs of $0.5 \mu \mathrm{g} / \mathrm{mL}$ (low level of resistance or borderline resistance). These strains presented oxacillin resistance between 0.5 and $2.0 \mu \mathrm{g} / \mathrm{mL}$, near the breakpoint for resistance.

In conclusion, though the phenotypic methods (manual or automated) are troublesome and time consuming, they are the most widely used in clinical laboratories, because they are easy to use. Molecular methods of identification of SCoN are still restricted to research laboratories and should be employed for the less prevalent species.

The cefoxitin disk test $(30 \mu \mathrm{g})$ gave the same sensitivity and better specificity than the oxacillin disk $(1 \mu \mathrm{g})$ for the detection of mecA-gene-mediated oxacillin resistance in SCoNne isolates. To improve the performance of the cefoxitin disk, concomitant use of cefoxitin (30 g) and oxacillin $(1 \mu \mathrm{g})$ in the clinical laboratory routine would reduce mistakes made in the detection of oxacillin resistance, restricting PCR or agglutination tests to PBP2a to resolve discrepancies between disk tests.

\section{Acknowledgments}

We thank the technical team of Laboratory of Gram-positive Cocci of the Universidade Federal de Ciências da Saúde de Porto Alegre (UFCSPA) and the Bacteriologia/Biologia Molecular Sections of Laboratório Weinmann, Porto Alegre/ RS for their help and support of this research.

\section{References}

1. Rupp M.E., Archer G.L. Coagulase-negative staphylococci: pathogens associated with medical progress. Clin Infect Dis 1994;19:231-45.

2. Marshall A.S., Wilke W.W., Pfaller M.A., Jones R.N. Staphylococcus aureus and Coagulase-Negative Staphylococci from blood stream infections: frequency of occurrence, antimicrobial susceptibility, and molecular (mecA) characterization of oxacillin resistance in the SCOPE Program. Diagn Microbiol Infect Dis 1998;30:205-14.

3. Campoccia D., Montanaro L., Arciola C.R. The significance of infection, related to orthopedic devices and issues of antibiotic resistance. Biomaterials 2006;27:2331-9.

4. Layer F., Ghebremedhin B., Moder K.A., et al. Comparative study using various methods for identification of Staphylococcus species in clinical specimens. J Clin Microbiol 2006;44:2824-30. 
5. Patel R., Piper K.E., Rouse M., et al. Frequency of isolation of Staphylococcus lugdunensis among Staphylococcal isolates causing endocarditis: a 20-years experience. J. Clin Microbiol 2000;38:4262-3.

6. Couto I., Pereira S., Miragaia M., et al. Identification of Clinical Staphylococcal isolates from humans by internal transcribed spacer PCR. J. Clin Microbiol 2001;39:3099-103.

7. Nunes A.P.F., Teixeira L.M., Iorio N.L.P., et al. Heterogeneous resistance to vancomycin in Staphylococcus epidermidis, Staphylococcus haemolyticus and Staphylococcus warneri clinical strains: characterization of glycopeptide susceptibility profiles and cell wall thickening. Int J Antimicrob Agents 2006;27:307-15.

8. Ferreira R.B.R., Nunes A.P.F., Kokis V.M., et al. Simultaneous detection of the mecA and ileS-2 genes in coagulase-negative staphylococci isolated from Brazilian hospitals by multiplex PCR. Diagn Microbiol Infect Dis 2002;42:205-12.

9. Sader H.S., Jones R.N., Gales A.C., et al. SENTRY Antimicrobial Surveillance Program Report: Latin American and Brazilian Results for 1997 trough 2001. Braz J Infect Dis 2004;8:25-79.

10. Chambers H.F. Methicilin Resistance in Staphylococci: molecular and biochemical basis and clinical implications. Clin Microbiol Rev 1997;10:781-91.

11. Skov R., Syth R., Larsen A.R., et al. Evaluation of cefoxitin 5 and $10 \mathrm{mg}$ discs for the detection of methicillin resistance in staphylococci. J Antimicrob Chemother 2005;13:1-5.

12. National Committee for Clinical Laboratory Standards Performance standards for antimicrobial susceptibility testing. Fourteenth informational supplement. NCCLS document M100S14. National Committee for Clinical Laboratory Standards, Wayne, PA, 2004.

13. Fernandes C.J., Fernandes L.A., Collignon P. Cefoxitin resistance as a surrogate marker for detection the detection of methicillinresistant Staphylococcus aureus. J Antimicrob Chemother 2005;55:506-10.

14. Swenson J.M., Tenover F.C., Cefoxitin disk Study Group. Results of disk diffusion testing with cefoxitin correlate with presence of mecA in Staphylococcus spp. J. Clin Microbiol 2005;43:3818-23.

15. Velasco D., Tomas M.M., Cartelle M., et al. Evaluation of different methods for detecting methicillin (oxacillin) resistance in Staphylococcus aureus. J Antimicrob Chemother 2005;55:379-82.

16. Kloos W., Bannerman T.L. Update and clinical significance of coagulse-negative staphylococci. Clin. Microbiol Rev 1994; 7:117-40.

17. Banermann T. Staphylococcus, Micrococcus and other catalasepositive cocci that grow aerobically. In: Murray P.R., Baron E.J., Jorgensen J.H., et al. eds. Manual of Clinical Microbiology. 8th. Washington, DC: American Society for Microbiology Press, 2003.

18. Antunes A.L.S., Secchi C., Reiter K.C., et al. Feasible identification of Staphylococcus epidermidis using desferrioxamine and fosfomycin disks. APMIS, 2007 (in press).

19. Poyart C., Quesne G., Boumaila C., Trieu-Cuot P. Rapid and Acute Species-Level identification of coagulase-negative staphylococci by using the $\operatorname{sodA}$ Gene as a Target. J. Clin Microbiol 2001;39:4296-4301.

20. Clinical and Laboratory Standards Institute/NCCLS. Performance standards for antimicrobial susceptibility testing. Fifteenth informational supplement. CLSI/NCCLS document M100-S15. Clinical and Laboratory Standards Institute, Wayne, PA, 2005.

21. Vannuffel P., Gigi J., Ezzedine H., et al. Specific detection of methicillin resistant Staphylococcus species by multiplex PCR. J. Clin Microbiol 1995;33:2864-7.
22. Fujita S.I., Senda Y., Iwagami T., Hashimoto T. Rapid identification of Staphylococcal Strains from positive-testing blood, culture bottles by internal transcribed spacer PCR followed by microchip gel electrophoresis. J Clin Microbiol 2005;43:1149-57.

23. Mougeot C., Guillaumat-Tailliet J., Libert J.M. Staphylococcus aureus: nouvelle detection de la résistance intrinseque par la méthode de diffusion. Pathol Biol 2001;49:199-204.

24. Felten A., Grandry B., Lagrange P.H., Casiro I. Evaluation of three techniques for detection of Low Level methicillinresistant Staphylococcus aureus (MRSA); a Disk Diffusion Method with Cefoxitin and Moxalactam, Vitek 2 System, and the MRSA-Screen latex Agglutination Test. J Clin Microbiol 2002;40:2766-71.

25. Cauwelier B., Gordts B., Descheemaeecker P., Van Landuyt H. Evaluation of disk diffusion method with cefoxitin $(30 \mu \mathrm{g})$ for detection of methicillin-resistant Staphylococcus aureus. Eur J Clin Microbiol Infect Dis 2004;23:389-92.

26. Ferreira R., Iorio N., Malvar K., et al. Coagulase-negative Staphylococci: comparison of phenotypic and genotypic oxacillin susceptibility tests and evaluation of the Agar screening test by using different concentration of oxacillin. J Clin. Microbiol 2003;41:3609-14.

27. Caierão J., Musskopf M., Roesch E., et al. Evaluation of phenotypic methods for methicillin resistance characterization in coagulase-negative staphylococci (CNS). J Med Microbiol 2004;53:1195-9.

28. Perez L.R., Antunes A.L., Barth A.L., d'Azevedo P.A. Variations of agar screen tests for detection of methicillin resistance in staphylococci: focus on cefoxitin. Eur J Clin Microb Infect Dis 2007;26:267-70.

29. Palazzo I.C.V., Darini A.L.C. Evaluation of methods for detecting oxacillin resistance in coagulase-negative staphylococci including cefoxitin disc diffusion. FEMS Microbiol Lett 2006;257:299-305.

30. Perazzi R., Fermepin M.R., Malimovka A., et al. Accuracy of cefoxitin disk testing fro characterization of oxacillin resistance mediated by Penicillin-Binding Protein 2a in coagulase-negative Staphylococci. J. Clin Microbiol 2006;44:3634-9.

31. Pottumarthy S., Fritsche T.R., Jones R.N. Evaluation of alternative disk diffusion methods for detecting mecA-mediated oxacillin resistance in an international collection of staphylococci: Validation report from the SENTRY Antimicrobial Surveillance Program Diagn Microbiol Infect Dis 2005;51:57-62.

32. Louie L., Majury A., Goodfellow J., et al. Evaluation of a latex agglutination test (MRSA-screen) for detection of oxacillin resistance in coagulase-negative staphylococci. J Clin Microbiol 2001;39;4149-51.

33. Tenover F.C., Jones R.N., Swenson J.M., et al. Methods for Improved Detection of Oxacillin Resistance in Coagulasenegative Staphyloccci: Results of Multicenter Study. J Clin Microbiol 1999;37:4051-58.

34. Hussain Z., Stoakes L., Massey V., et al. Correlation of oxacillin MIC with mecA gene carriage in Coagulase-negative Staphylococci. J Clin Microbiol 2000;38:752-4.

35. National Committee for Clinical Laboratory Standards. Performance standards for antimicrobial susceptibility testing. Eleventh informational supplement. NCCLS document M100S11. National Committee for Clinical Laboratory Standards, Wayne, PA, 2001.

36. Hussain Z., Stoakes L., John M.A., et al. Detection of methicillin in primary blood cultures isolates of Coagulase-negative Staphylococci by PCR, Slide Agglutination, Disk Diffusion, and a commercial method. J Clin Microbiol 2002;40:2251-3. 